Xiaowei Song, $\mathrm{PhD}$

Arnold Mitnitski, PhD

Kenneth Rockwood,

MD

Address correspondence and reprint requests to Dr. Kenneth Rockwood, QEII Health Sciences Centre, Division of Geriatric Medicine, Suite 1421-5955 Veterans Memorial Lane, Halifax, Nova Scotia, B3H 2E1, Canada Kenneth.Rockwood@dal.ca

Editorial, page 206

See pages 212 and 219

Supplemental data at www.neurology.org

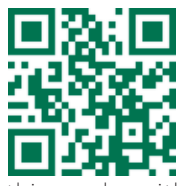

Scan this code with your smartphone to access this feature

\section{Nontraditional risk factors combine to predict Alzheimer disease and dementia}

\section{ABSTRACT}

Objective: To investigate whether dementia risk can be estimated using only health deficits not known to predict dementia.

Methods: A frailty index consisting of 19 deficits not known to predict dementia (the nontraditional risk factors index [FI-NTRF]) was constructed for 7,239 cognitively healthy, communitydwelling older adults in the Canadian Study of Health and Aging. From baseline, their 5-year and 10-year risks for Alzheimer disease (AD), dementia of all types, and survival were estimated.

Results: The FI-NTRF was closely correlated with age $\left(r^{2}>0.96, p<0.001\right)$. The incidence of AD and dementia increased exponentially with the FI-NTRF ( $r^{2}>0.75, p<0.001$ over 10 years). Adjusted for age, sex, education, and baseline cognition, the odds ratio of dementia increased by $3.2 \%(p=0.021)$ for each deficit (that was not known to predict dementia) accumulated, outperforming the individual cognitive risk factors. The FI-NTRF discriminated people with AD and allcause dementia from those who were cognitively healthy with an area under the receiver operating characteristic curve of $0.66 \pm 0.03$

Conclusions: Comprehensive re-evaluation of a well-characterized cohort showed that ageassociated decline in health status, in addition to traditional risk factors, is a risk factor for AD and dementia. General health may be an important confounder to consider in dementia risk factor evaluation. If a diverse range of deficits is associated with dementia, then improving general health might reduce dementia risk. Neurology ${ }^{\circledR} 2011 ; 77: 227-234$

\section{GLOSSARY}

3MS = Modified Mini-Mental State Examination; $\mathbf{A D}=$ Alzheimer disease; $\mathbf{A R}=$ attributable risk; $\mathbf{A U C}=$ area under the curve; $\mathbf{C l}=$ confidence interval; $\mathbf{C S H A}=$ Canadian Study of Health and Aging; $\mathbf{D S M}-\mathbf{I I I}-\mathbf{R}=$ Diagnostic and Statistical Manual of Mental Disorders, 3rd edition, revised; FI-NTRF = frailty index of nontraditional risk factors; OR = odds ratio; ROC = receiver operating characteristic.

Age remains the single most potent risk factor for late-onset Alzheimer disease (AD). This is so even though many age-related health problems, such as heart disease, hypertension, stroke, and diabetes, are recognized as $\mathrm{AD}$ risk factors. ${ }^{1,2}$ To this list, other problems common in older people might be added: high plasma cholesterol, morning cough, a sedentary lifestyle, pesticide exposure, dementia in a spouse, and feeling tired, lonely, or unwell have each also been reported to increase the risk of dementia. ${ }^{3-8}$

The diversity of risks for late-life dementia, and in particular $\mathrm{AD}$, may itself be informative. Their broad range suggests that $\mathrm{AD}$ is more likely in people with a broadly constituted decline in health. Support for this hypothesis comes from studies that link frailty to dementia, ${ }^{9}$ and more generally, to cognitive decline,${ }^{10}$ and from a recent review which found that dementia risk was best predicted by models that used multiple risk factors. ${ }^{11}$

If most known risk factors individually discriminate people at risk only poorly, ${ }^{11}$ there may be merit in using an integrative approach to their evaluation. In studies of aging, the frailty

From the Departments of Medicine (X.S., A.M., K.R.) and Mathematics and Computer Science (A.M.), Dalhousie University, Halifax; Institute for Biodiagnostics-Atlantic (X.S.), National Research Council Canada, Halifax; and Centre for Health Care of Elderly (K.R.), QEII Health Sciences Centre, Halifax, Canada.

Study funding: Supported by operating grants from the Canadian Institutes of Health Research (MOP-209888) and the Nova Scotia Health Research Foundation (MED2006-2086), and by a fellowship from the Alzheimer Society of Canada. K.R. receives funding from the Dalhousie Medical Research Foundation as Kathryn Allen Weldon Professor of Alzheimer Research.

Disclosure: Author disclosures are provided at the end of the article. 


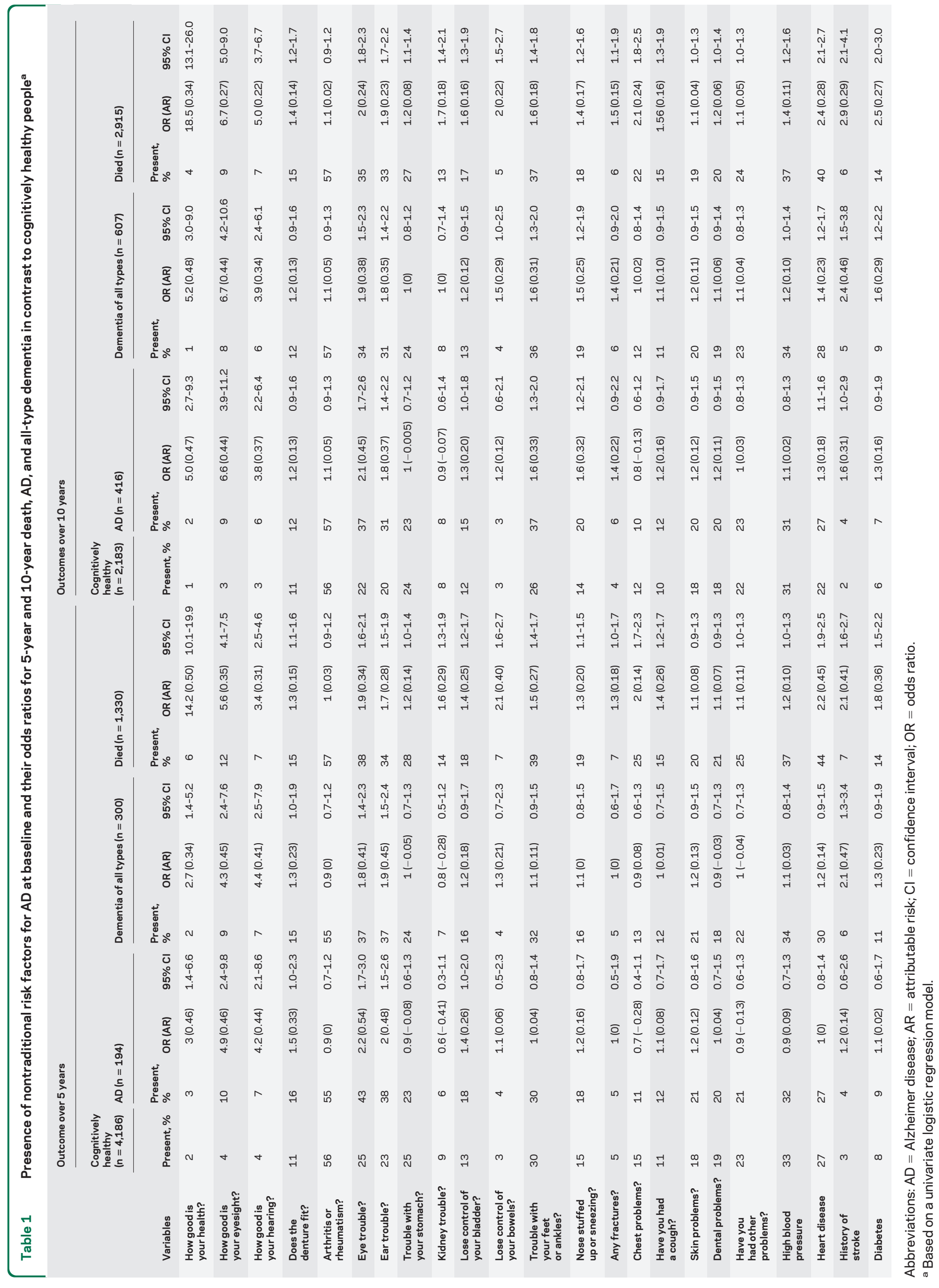


index has proven powerful, as it integrates both large and small effects, thereby allowing risk to be estimated in a larger range of people than when fewer factors are considered. ${ }^{12,13}$ Our objective was to examine whether decline in health, assessed by a frailty index made up only of attributes that are not known as cognitive risk factors, predicts the incidence of dementia as well as do traditional risk factors.

METHODS Participants. This is a re-evaluation of the $\mathrm{Ca}$ nadian Study of Health and Aging (CSHA), a well-characterized dementia epidemiology study. The CSHA assembled a representative cohort of 10,263 participants in 1991/1992 (CSHA-1). ${ }^{14}$ Five-year follow-ups occurred in 1996/1997 (CSHA-2) and 2001/2002 (CSHA-3). ${ }^{15,16}$ At baseline, 9,008 communitydwelling older adults were screened using a questionnaire that included the modified Mini-Mental State Examination (3MS); people who had $3 \mathrm{MS}$ total score $\leq 78$ were invited to a cognitive examination. Of 7,239 people who were cognitively healthy at baseline, by CSHA-2, 5,609 were available; by CSHA-3, 3,883.
Cognitive healthy samples were further analyzed for AD-dementia risks at each follow-up (figure e-1 on the Neurology ${ }^{\circledR}$ Web site at www.neurology.org).

Health measures (deficits). The health of older adults can be quantified by counting their health deficits. Deficits can be symptoms, signs, or laboratory or other measures. The resulting deficit accumulation index variable, i.e., a frailty index, ${ }^{12,13}$ was adapted for this study. A frailty index quantifies health status, and characterizes the risk of adverse outcomes, including death, institutionalization, and further deficit accumulation..$^{13}$ To be included in the frailty index as a deficit, any health variable must show that its prevalence increases with age, that it does not saturate too early (i.e., that it does not become too prevalent at some younger age), and that it is associated with adverse outcomes. ${ }^{17} \mathrm{~A}$ further restriction for constructing the current version of the frailty index was that each deficit had to be not known as a dementia risk factor. Deficits came from 19 variables used in the CSHA-1 screening questionnaire (table 1). Each self-reported medical condition, disease history, symptom, and health rating variable satisfied the criteria for being a deficit. Deficits that typically would be included in a frailty index but which were excluded here were cognitive measures (e.g., memory loss,

\section{Table 2 Characteristics of the cognitively healthy sample at baseline}

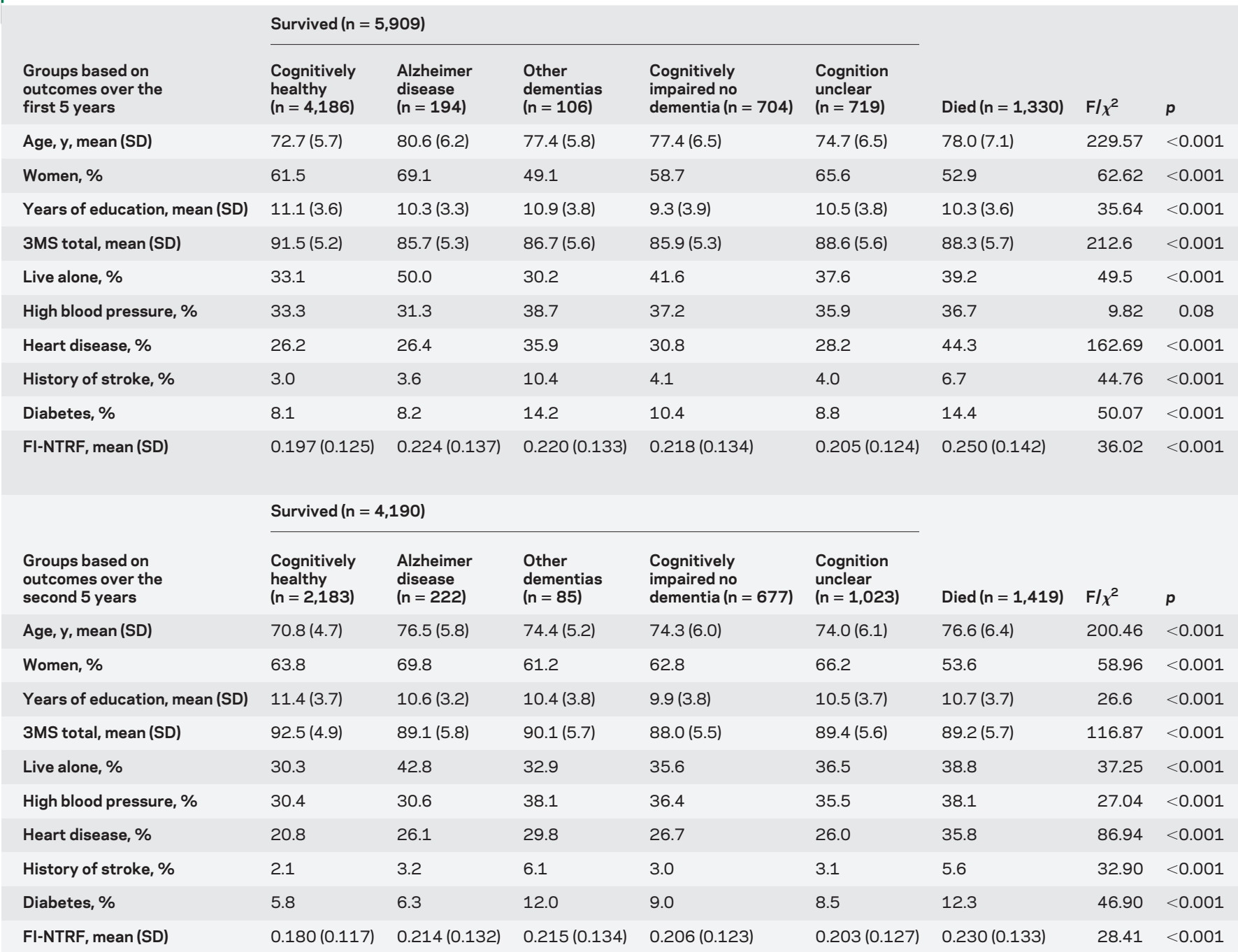

Abbreviation: FI-NTRF $=$ frailty index of nontraditional risk factors. 
language problems), cognitive risk factors (e.g., hypertension, heart disease, stroke, diabetes), social vulnerability measures (e.g., socioeconomic status), deadly diseases (e.g., cancer), functional disability measures (e.g., impairment in basic and instrumental activities of daily living), or dementia predictors (e.g., tiredness and symptoms of depression).

The frailty index of 19 nontraditional dementia risk factors (FI-NTRF) was constructed by first coding each variable to an interval from 0 to 1 . For the 16 -level variables, "1" indicates that the problem is present and " 0 " that it is absent. The 3 5-level variables (e.g., "how is your health these days?") were dichotomized with " 1 " representing "not too good," "poor," or "very poor" and "0" representing "pretty good" or "very good."

Figure 1 Rates of death and Alzheimer disease $(A D)$ dementia

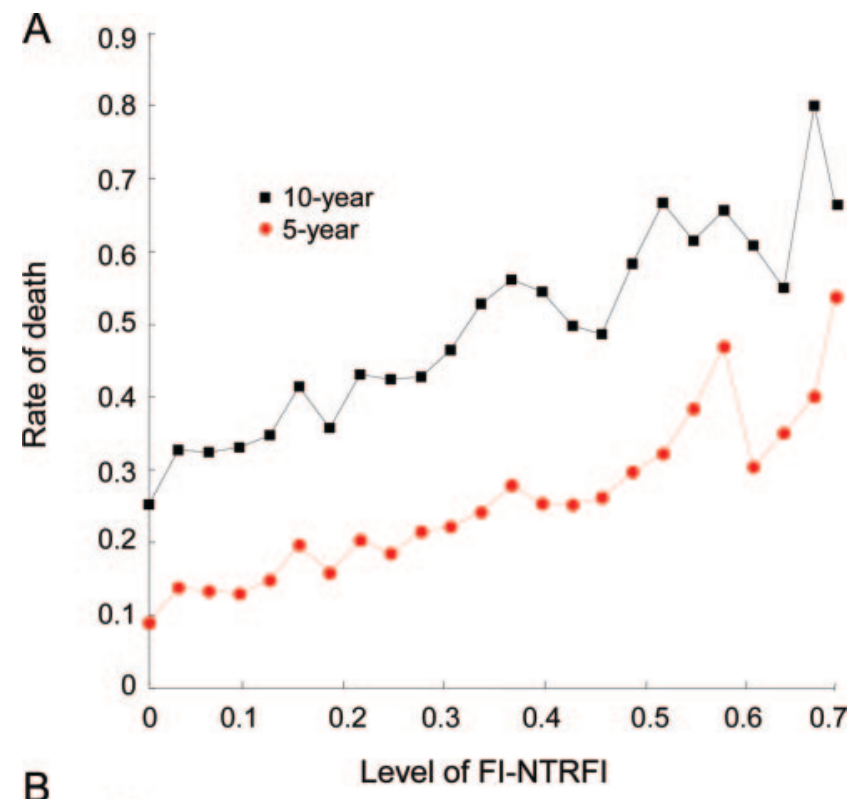

B

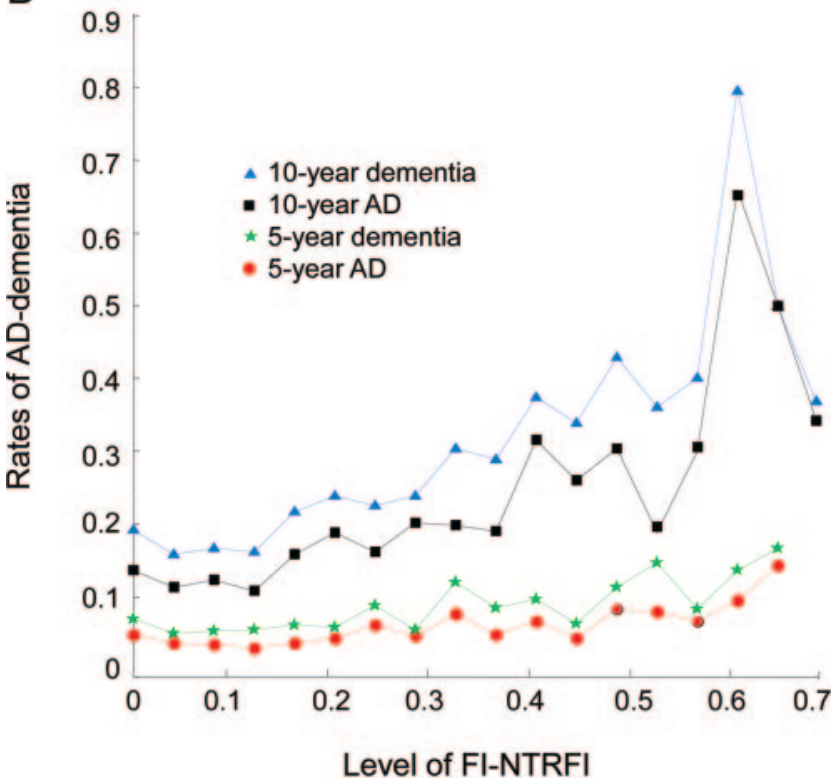

(A) Five-year (circles) and 10-year (squares) rates of death as a function of the frailty index of nontraditional risk factors (FI-NTRF). (B) Rate of AD after 5 years (circles) and 10 years (squares), and rates of all types of dementia after 5 years (stars) and 10 years (triangles) as a function of the FI-NTRF. Symbols represent observational data as averaged by each 0.03 increment of the FI-NTRF.
The maximum number of missing cases was $0.6 \%$, seen in one variable. Of the 7,239 cognitively healthy people, 7,071 (i.e., $97.8 \%)$ had no missing values. Missing values were imputed using the nonmissing mean of the variable; the effect of each variable in the sample was examined for sensitivity and no significant difference was found before and after imputation $(p>0.05)$. Each person's FI-NTRF score was calculated as the proportion of deficits present (see expression below, where $\mathrm{n}=19, X_{i}$ refers to a deficit) so that someone with no deficits would have an FI-NTRF score of 0 , whereas in the hypothetical case of someone having all 19 deficits, the score would be 1 .

$$
\text { FI-NTRF }=\frac{1}{n} \sum_{i=1}^{n} x_{i}
$$

Known cognitive risk factors including high blood pressure, heart disease, stroke, and diabetes were coded in the same manner as 2-level variables (i.e., $1=$ problem present, $0=$ problem absent), for comparison in the risk models.

Outcomes. The major outcomes were survival (i.e., died or survived) and cognitive status (e.g., $\mathrm{AD}$, dementia, cognitive healthy) over each of the 5-year and 10-year follow-ups. Dementia and $\mathrm{AD}$ were defined according to established criteria (respectively, National Institute of Neurological and Communicative Disorders and Stroke-Alzheimer's Disease and Related Disorders Association and DSM-III-R, as elaborated elsewhere ${ }^{14-16}$ ). Decedent data were obtained from the Registrar of Vital Statistics in each province in addition to interviews of spouses or next of kin of the study participants who had died.

Standard protocol approvals, registrations, and patient consents. Data collection was approved by the CSHA ethics review process, with informed consent provided by all participants. Approval for the secondary analyses came from the Research Ethics Committee of the Capital District Health Authority, Halifax, Nova Scotia, Canada.

Statistical analysis. Logistic regression was used to estimate the likelihood and 95\% confidence intervals (CI) of each deficit variable individually, regarding to various outcomes, while the attributable risk (AR) was evaluated as the fraction of the differential risk between exposed and unexposed over the risk for exposed..$^{18}$ Multivariable logistic regression models were used to analyze the likelihoods of the FI-NTRF for cognitive and survival outcomes, with which the virtually continuous FI-NTRF ranging between 0 and 1 was converted to graded 1-30 integers by rounding FI-NTRF after multiplying it by 30 , so that it would match each year's age increment (i.e., age and the FI-NTRF had the same number of intervals). Different subsets of cofounders (e.g., age, sex, education, 3MS score, and the cognitive risk factors) were used to adjust for the risk models, where sex, low education ( $<9$ years of schooling), and cognitive risks were applied as discrete variables. Analysis of variance and the $\chi^{2}$ test were used to compare group differences with interval or categorical variables, respectively. Multiple comparisons were performed using Tukey test to examine paired-wise group differences in the means. The age-specific distribution of the FI-NTRF was estimated as the mean of the index, with 2- to 3-year aggregated intervals from age 65 . Changes in the rate of death and in the ratio of $\mathrm{AD}$ dementia in relation to the FI-NTRF were analyzed using regression models. Sensitivity analyses were conducted on the FI-NTRF and on individual cognitive risk factors to assess positive and negative predictive rates in predicting dementia and survival outcomes. Performance of the FI-NTRF in discriminating individuals who died from survivors and individuals who had $\mathrm{AD}$ dementia 
from those who maintained cognitive health was evaluated using receiver operating characteristic (ROC) curves, with accuracy assessed based on the areas under the curve (AUCs).

Analyses were performed using codes developed in MATLAB (version 2007, MathWorks Inc.). Other software applied in data preparation and analysis included SPSS (version 15.0, SPSS Inc.) and SAS (version 9.0, SAS Institute Inc.). Statistical significance level was set at $p=0.05$.

RESULTS When considered individually, most health deficits showed an insignificant risk for adverse outcomes (table 1). When they were combined, a higher level of the FI-NTRF was observed in people who later died or developed $\mathrm{AD}$ dementia. Compared with survivors, subjects who died were older, more often men, and had less education, a lower 3MS score, and both more traditional cognitive risk factors and a higher FI-NTRF score (table 2). Even though subjects who developed $\mathrm{AD}$ were of a similar mean age at baseline to those who died, they were more likely to be women and to have lived alone; this last trait was in contrast to those who died or developed non-AD dementia (table 2). The proportion with known cognitive risk factors was lower in $\mathrm{AD}$ than in non-AD dementia; each was higher than in the healthy group. People who developed AD and

\section{Figure 2 Receiver operating characteristic (ROC) curves}

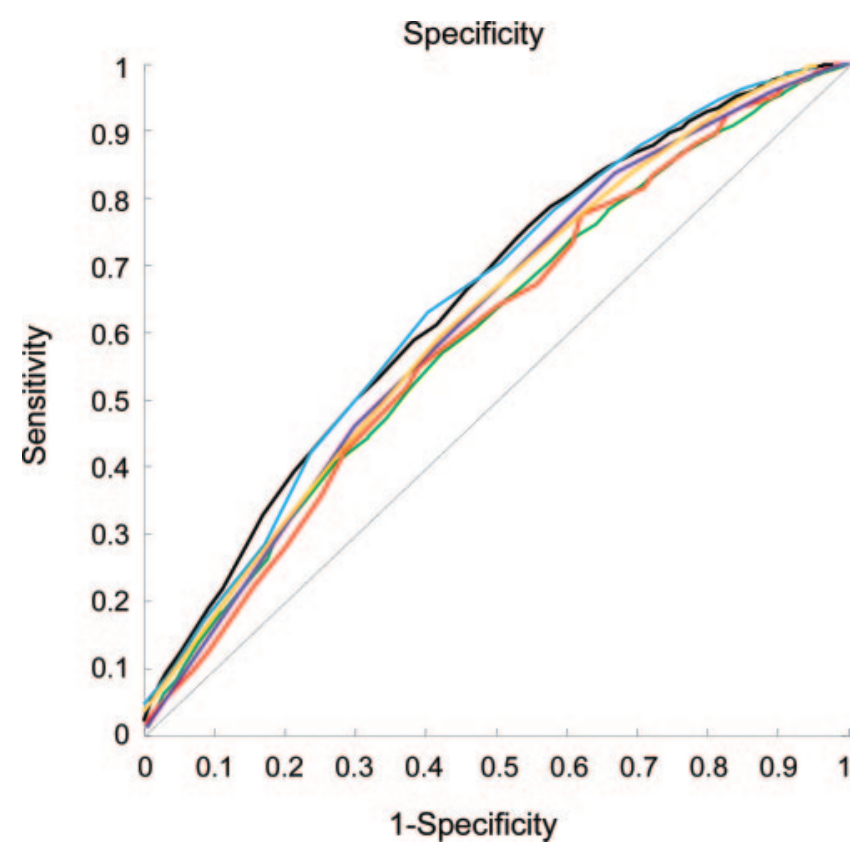

ROC curves showing the performance of the frailty index of nontraditional risk factors in predicting individuals who died vs those who survived and in predicting individuals who developed Alzheimer disease (AD) or all types of dementia vs those who remained cognitively healthy. The areas under the curve (mean AUC \pm standard error) were $0.68 \pm 0.02$ for death within 5 years (black line); $A \cup C=0.65 \pm 0.01$ for death within 10 years (blue line); $A U C=0.64 \pm 0.03$ for $A D$ within 5 years (red line); $A U C=0.66 \pm 0.03$ for $A D$ within 10 years (orange line); $A U C=0.64 \pm 0.03$ for dementia within 5 years (green line); $A \cup C=0.66 \pm 0.03$ for dementia within 10 years (purple line). The diagonal line indicates AUC $=0.50$.
non-AD dementia had similar levels of FI-NTRF, and for both groups it was higher than for those who remained cognitively healthy. People with cognitive impairment but not dementia had an intermediate level of deficit accumulation. These relationships with baseline characteristics were consistent for both CSHA-1/2 and CSHA 2/3 follow-ups (table 2).

The mean level of the FI-NTRF increased with age $\left(r^{2}>0.96, p<0.001\right)$. In general, people who maintained cognitive health over 10 years were healthier at baseline (i.e., had lower FI-NTRF scores) than those who died or developed dementia. The rate of death over 5 or 10 years increased with the increase in the FI-NTRF (figure 1A). The risk of AD or of all-type dementia (figure 1B) also increased with the FI-NTRF; the strongest correlation was observed for the 10-year $\left(r^{2}>0.75, p<0.001\right)$ follow-up (figure 1B).

Traditional cognitive risk factors predicted survival and cognitive outcomes with variable performance (table e-1). Compared to the specificity and negative predictive values, the sensitivity and positive predictive values were generally low, particularly for 5-year AD dementia prediction. Predicting the outcomes using a dichotomized frailty index (e.g., FI-NTRF $\leq 0.3$ vs $>0.3$ ) resulted in comparable performances for all outcome measures (table e-1). The AUC for the FI-NTRF in discriminating individuals with various outcomes indicated moderate performance (figure 2).

When only age, FI-NTRF, and sex were included, the FI-NTRF increased the risk of death, AD, and all-cause dementia, supplanting the effect of age. Men had both a higher risk of death and a lower risk of $\mathrm{AD}$, but not a lower risk of the other dementias (model 1 in table 3 and table e-2). After adjusting for low education and a lower 3MS score, the FI-NTRF was still associated with an increased risk of death and dementia (model 2 in table 3). A significant impact of age on the outcomes was also clear. Note that including traditional dementia risk factors lowered the relative risks of the FI-NTRF, suggesting a close association of these risk factors with the FI-NTRF; even so, the FI-NTRF yielded statistically significant $\mathrm{AD}$ risk estimates, and outperformed the traditional cognitive risk factors (model 3 in table 3).

DISCUSSION We evaluated several health deficits that are not known to be risks for dementia, and found that, combined in an index variable, they were significantly associated not just with survival, but also with the incidence of $\mathrm{AD}$ and dementia of all types over 5-year and 10-year intervals. These associations were maintained even after adjusting for traditional risk factors and for age. 


\begin{tabular}{|c|c|c|c|c|c|c|c|c|c|c|c|c|c|c|c|}
\hline \multirow{3}{*}{$\begin{array}{l}\text { Table } 3 \\
\text { Covariates }\end{array}$} & \multicolumn{15}{|c|}{ r prediction } \\
\hline & \multicolumn{5}{|c|}{ Death vs survival $(n=7,239)$} & \multicolumn{5}{|c|}{$\begin{array}{l}\text { Alzheimer disease vs } \\
\text { cognitively healthy }(n=2,599)\end{array}$} & \multicolumn{5}{|c|}{$\begin{array}{l}\text { All types of dementia vs } \\
\text { cognitively healthy }(n=2,790)\end{array}$} \\
\hline & OR & \multicolumn{2}{|c|}{$95 \% \mathrm{Cl}$} & Wald & $p$ & OR & \multicolumn{2}{|c|}{$95 \% \mathrm{Cl}$} & Wald & $p$ & OR & \multicolumn{2}{|c|}{$95 \% \mathrm{Cl}$} & Wald & $p$ \\
\hline \multicolumn{16}{|l|}{ Model 1} \\
\hline Age & 1.00 & 0.99 & 1.00 & 27.9 & 0.000 & 0.98 & 0.97 & 0.98 & 231.4 & 0.000 & 0.98 & 0.98 & 0.98 & 209.1 & 0.000 \\
\hline FI-NTRF & 1.07 & 1.06 & 1.09 & 126.7 & 0.000 & 1.03 & 1.01 & 1.05 & 6.0 & 0.014 & 1.03 & 1.01 & 1.05 & 10.7 & 0.001 \\
\hline Male & 1.47 & 1.31 & 1.65 & 43.2 & 0.000 & 0.66 & 0.53 & 0.83 & 13.0 & 0.000 & 0.94 & 0.80 & 1.01 & 3.2 & 0.066 \\
\hline \multicolumn{16}{|l|}{ Model 2} \\
\hline Age & 1.16 & 1.15 & 1.17 & 906.8 & 0.000 & 1.20 & 1.18 & 1.22 & 389.9 & 0.000 & 1.19 & 1.17 & 1.21 & 463.4 & 0.000 \\
\hline FI-NTRF & 1.07 & 1.05 & 1.08 & 80.4 & 0.000 & 1.02 & 1.00 & 1.05 & 4.1 & 0.059 & 1.02 & 1.01 & 1.05 & 5.6 & 0.021 \\
\hline Male & 2.16 & 1.88 & 2.48 & 120.6 & 0.000 & 1.15 & 0.88 & 1.52 & 1.0 & 0.309 & 1.38 & 1.10 & 1.73 & 7.5 & 0.006 \\
\hline Education $<9 y$ & 1.22 & 1.04 & 1.43 & 5.8 & 0.016 & 1.41 & 1.05 & 1.88 & 5.2 & 0.023 & 1.36 & 1.05 & 1.75 & 5.6 & 0.018 \\
\hline 3MS total & 0.88 & 0.87 & 0.89 & 957.9 & 0.000 & 0.84 & 0.83 & 0.85 & 463.2 & 0.000 & 0.85 & 0.84 & 0.86 & 543.7 & 0.000 \\
\hline \multicolumn{16}{|l|}{ Model 3} \\
\hline Age & 1.17 & 1.16 & 1.18 & 946.0 & 0.000 & 1.20 & 1.18 & 1.23 & 354.4 & 0.000 & 1.20 & 1.18 & 1.22 & 460.6 & 0.000 \\
\hline FI-NTRF & 1.05 & 1.03 & 1.06 & 31.5 & 0.000 & 1.01 & 1.00 & 1.03 & 3.6 & 0.063 & 1.02 & 1.01 & 1.04 & 4.5 & 0.044 \\
\hline Male & 2.19 & 1.90 & 2.52 & 118.4 & 0.000 & 1.13 & 0.85 & 1.49 & 1.0 & 0.408 & 1.37 & 1.09 & 1.73 & 7.0 & 0.008 \\
\hline Education $<9 y$ & 1.18 & 1.01 & 1.39 & 4.2 & 0.042 & 1.37 & 1.02 & 1.83 & 4.7 & 0.038 & 1.33 & 1.03 & 1.71 & 4.7 & 0.031 \\
\hline 3MS total & 0.89 & 0.89 & 0.90 & 655.9 & 0.000 & 0.85 & 0.83 & 0.86 & 387.5 & 0.000 & 0.86 & 0.85 & 0.87 & 440.0 & 0.000 \\
\hline High blood pressure & 0.83 & 0.72 & 0.97 & 5.7 & 0.017 & 1.00 & 0.75 & 1.32 & 0.0 & 0.981 & 0.94 & 0.74 & 1.19 & 0.3 & 0.587 \\
\hline Heart disease & 0.58 & 0.49 & 0.68 & 46.4 & 0.000 & 0.94 & 0.69 & 1.28 & 0.0 & 0.715 & 0.88 & 0.68 & 1.14 & 1.0 & 0.323 \\
\hline History of stroke & 0.53 & 0.36 & 0.77 & 11.0 & 0.001 & 0.69 & 0.35 & 1.36 & 0.8 & 0.279 & 0.50 & 0.29 & 0.87 & 6.1 & 0.013 \\
\hline Diabetes & 0.39 & 0.31 & 0.50 & 56.0 & 0.000 & 0.64 & 0.39 & 1.03 & 2.9 & 0.067 & 0.54 & 0.37 & 0.81 & 9.0 & 0.003 \\
\hline
\end{tabular}

Abbreviations: $3 \mathrm{MS}=$ Modified Mini-Mental State Examination; $\mathrm{Cl}=$ confidence interval; FI-NTRF $=$ frailty index of nontraditional risk factors; $\mathrm{OR}=$ odds ratio.

Our data have acknowledged limitations in lacking autopsy validation and routine neuroimaging. Conversely, the screening and clinical examination protocol was carefully considered and executed, and combined neuropsychological information in a consensus diagnosis. Moreover, the data have stood for many years as informing our understanding of the epidemiology of dementia. ${ }^{16,19-22}$ We noted differences in the relative contributions of the FI-NTRF in predicting cognition and death. In contrast to death, which was better predicted over the shorter term, cognition was better predicted over the longer term, reflecting a possible effect of competing outcomes. Our data record the exact date of death, but do not record the date of onset of dementia, which introduces a bias: people who died included those who had developed dementia before death. At present, the data are themselves old (data collection finished in 2002) but, being from a large, well-characterized dementia epidemiology study, are an appropriate focus for systematic re-evaluation.

Although the frailty index approach has been multiply cross-validated by ourselves and by other groups, ${ }^{13,14}$ it has not been applied to evaluate dementia and so will be new to many readers. The first test, therefore, is to check the internal validity of the results. These seem secure. First, the FI-NTRF shows all the properties that are characteristic of any standard frailty index. ${ }^{13}$ Second, this report joins others from the Rush Memory and Aging Project in suggesting that frailty is a risk for AD. ${ }^{9,10}$ It extends that information by not including items from how frailty was defined in that those studies (such as weight loss and motor slowing) which are known as dementia risk factors. ${ }^{23,24}$ Similarly, the FI-NTRF does not include disability items, which are often counted as deficits in a frailty index, or used in other frailty definitions. ${ }^{13}$ Most importantly, the relationship between the total number of nontraditional risk factors and dementia is robust: it is statistically significant, shows a dose-response relationship, holds across outcomes, and was similar in the interval between both CSHA 1-2 and CSHA 2-3. What is more, the relationship between nontraditional risk factors and mortality or dementia risk largely holds when those individual risks that are associated with dementia are included. This last, we recognize, turns on its head the tradition of studying factors in isolation, and then including only those found to be significantly associated with dementia in a multivariable model to obtain a final reckoning of which factors are important. That approach, however, is coming under ques- 
tion, chiefly because single factor analyses typically have low explanatory value compared with models that incorporate many risk factors. ${ }^{11}$ Here, accumulating any health deficit seemingly remote to dementia increases the risk of dementia by over 3\%. The explanatory value (ROCs of 0.66 ) is compatible with what has been reported for only traditional risk factors. This deficit accumulation approach finds its rationale in the idea that information which might, on its own, be only weakly associated with dementia can still contribute to a significant cumulative effect. ${ }^{25,26}$

The cumulative effects of sometimes small and cognitively irrelevant insults is in general compatible with the idea that factors which take a toll on general bodily health also are associated with-or set up the conditions for-factors that give rise to dementia. In this way, these data also draw attention to the possibility that improving the overall health of the population might lessen the burden of late-life dementia. ${ }^{27}$ The very broad nature of the range of factors that give rise to dementia suggests, at a minimum, that general health may be an important confounder to consider in evaluating dementia risk, especially with older samples, so that a more comprehensive view of health needs to be considered. In this regard, a frailty index allows for many dimensions to be summarized in a single variable, using data that are commonly collected in health surveys. ${ }^{13}$ It is clear that factors as diverse as vascular risks to social vulnerability are implicated in dementia. These factors seem chiefly to share either a broadly construed mechanistic riske.g., stress ${ }^{7}$ - or the ability to induce the need for repair, with disease arising as a consequence of aberrant repair processes. ${ }^{28}$ A broad view of how to approach dementia epidemiology seems particularly important, given that on a population basis, most dementia occurs in very late life, by which time many interacting medical and social problems commonly have accumulated. ${ }^{12}$ Given that mixed dementia is often the most common form of dementia, ${ }^{29-31}$ it is essential that we consider approaches which can take a multiplicity of causes into account, and to relate these to mechanisms. How best to model the impact of multiple, age-related causes represents a considerable challenge which is motivating additional inquiries by our group.

\section{AUTHOR CONTRIBUTIONS}

Dr. Song: drafting/revising the manuscript, analysis or interpretation of data, statistical analysis, obtaining funding. Dr. Mitnitski: analysis or interpretation of data, statistical analysis. Dr. Rockwood: drafting/revising the manuscript, study concept or design, analysis or interpretation of data, acquisition of data, study supervision, obtaining funding.

\section{ACKNOWLEDGMENT}

Data reported in this article were collected as part of the Canadian Study of Health and Aging, which was funded by the Seniors' Independence
Research Program, through the National Health Research and Development Program (NHRDP) of Health Canada (6606-3954-MCS). The study was coordinated through the University of Ottawa and the Division of Aging and Seniors from Health Canada.

\section{DISCLOSURE}

Dr. Song receives research support from Nova Scotia Health Research Foundation, Capital District Health Authority Research Foundation, and Alzheimer's Society of Canada. Dr. Mitnitski serves as an Associate Editor for BMC Geriatrics and Current Gerontology \& Geriatric Research and serves as Director Data Mining for DementiaGuide Inc. Dr. Rockwood serves on a DSMB for NUMCIO Plc, the Netherlands, and on a scientific advisory board for Elan Corporation/Wyeth; has received a speaker honorarium from Bristol-Myers Squibb; serves on the editorial boards of Neuroepidemiology, Age and Ageing, Alzheimer's Research \& Therapy, and BMC Medicine, and as founding chair of the international editorial advisory committee for the Chinese Journal of Geriatrics; serves as President \& Chief Scientific Officer of and shareholder in DementiaGuide, Inc.; receives research support from Canadian Institutes of Health Research, the National Natural Science Foundation of China, Alzheimer Society of Canada, Queen Elizabeth II Health Sciences Foundation, and Dalhousie Medical Research Foundation; and served as an expert witness for Tory's LLP, on behalf of Eisai Inc. and Pfizer Inc Canada.

Received September 17, 2010. Accepted in final form December 22, 2010

\section{REFERENCES}

1. Knopman DS, Roberts R. Vascular risk factors: imaging and neuropathologic correlates. J Alzheimers Dis 2010;20: 699-709.

2. Skoog I, Gustafson D. Hypertension, hypertensionclustering factors and Alzheimer's disease. Neurol Res 2003;25:675-680.

3. McDowell I. Alzheimer's disease: insights from epidemiology. Aging 2001;13:143-162.

4. Tilvis RS, Kahonen-Vare MH, Jolkkonen J, Valvanne J, Pitkala KH, Strandberg TE. Predictors of cognitive decline and mortality of aged people over a 10-year period. J Gerontol A Biol Sci Med Sci 2004;59:268-274.

5. Flicker L. Modifiable lifestyle risk factors for Alzheimer's disease. J Alzheimers Dis 2010;20:803-811.

6. Kamat SM, Kamat AS, Grossberg GT. Dementia risk prediction: are we there yet? Clin Geriatr Med 2010;26:113-123.

7. Qiu C, Xu W, Fratiglioni L. Vascular and psychosocial factors in Alzheimer's Disease: Epidemiological evidence toward intervention. J Alzheimers Dis 2010;20:689-697.

8. Hayden KM, Norton MC, Darcey D, et al. Occupational exposure to pesticides increases the risk of incident AD: the Cache County study. Neurology 2010;74:1524-1530.

9. Buchman AS, Boyle PA, Wilson RS, Tang Y, Bennett DA. Frailty is associated with incident Alzheimer's disease and cognitive decline in the elderly. Psychosom Med 2007;69: 483-489.

10. Buchman AS, Schneider JA, Leurgans S, Bennett DA. Physical frailty in older persons is associated with Alzheimer disease pathology. Neurology 2008;71:499-504.

11. Stephan BC, Kurth T, Matthews FE, Brayne C, Dufouil C. Dementia risk prediction in the population: are screening models accurate? Nat Rev Neurol 2010;6:318-326.

12. Mitnitski A, Song X, Skoog I, et al. Relative fitness and frailty of elderly men and women in developed countries and their relationship with mortality. J Am Geriatr Soc 2005;53:2184-2189.

13. Rockwood K, Mitnitski A. Frailty in relation to the accumulation of deficits. J Gerontol A Biol Sci Med Sci 2007; 62:722-727. 
14. Canadian Study of Health and Aging Working Group. Canadian Study of Health and Aging: study methods and prevalence of dementia. CMAJ 1994;150:899-913.

15. Canadian Study of Health and Aging Working Group. Canadian Study of Health and Aging. Int Psychogeriatr 2001;suppl 1:1-237.

16. Canadian Study of Health and Aging. The Canadian Study of Health and Aging: risk factors for Alzheimer's disease in Canada. Neurology 1994;44:2073-2080.

17. Searle SD, Mitnitski A, Gahbauer EA, Gill TM, Rockwood K. A standard procedure for creating a frailty index. BMC Geriatr 2008;8:24.

18. Kelsey JL, Whittemore AS, Evans AS, Thompson DW. Methods in Observational Epidemiology, 2nd ed. Oxford: Oxford University Press; 1996.

19. Lindsay J, Laurin D, Verreault R, et al. Risk factors for Alzheimer's disease: a prospective analysis from the Canadian Study of Health and Aging. Am J Epidemiol 2002; 156:445-453.

20. Laurin D, Verreault R, Lindsay J, MacPherson K, Rockwood K. Physical activity and risk of cognitive impairment and dementia in elderly persons. Arch Neurol 2001;58: 498-504.

21. Lindsay J, Hébert R, Rockwood K. The Canadian Study of Health and Aging: risk factors for vascular dementia. Stroke 1997;28:526-530.

22. Tierney MC, Yao C, Kiss A, McDowell I. Neuropsychological tests accurately predict incident Alzheimer disease after 5 and 10 years. Neurology 2005;64:1853-1859.
23. Knopman DS, Edland SD, Cha RH, Petersen RC, Rocca WA. Incident dementia in women is preceded by weight loss by at least a decade. Neurology 2007;69:739-746.

24. Camicioli R, Howieson D, Oken B, Sexton G, Kaye J. Motor slowing precedes cognitive impairment in the oldest old. Neurology 1998;50:1496-1498.

25. Kulminski AM, Ukraintseva SV, Kulminskaya IV, Arbeev KG, Land K, Yashin AI. Cumulative deficits better characterize susceptibility to death in elderly people than phenotypic frailty: lessons from the Cardiovascular Health Study. J Am Geriatr Soc 2008;56:898-903.

26. Song X, Mitnitski A, Cox J, Rockwood K. Comparison of machine learning techniques with classical statistical models in predicting health outcomes. Stud Health Technol Inform 2004;107:736-740.

27. Fratiglioni L, Paillard-Borg S, Winblad B. An active and socially integrated lifestyle in late life might protect against dementia. Lancet Neurol 2004;3:343-353.

28. Rockwood K. Lessons from mixed dementia. Int Psychogeriatr 1997;9:245-249.

29. Fernando MS, Ince PG, MRC Cognitive Function and Ageing Neuropathology Study Group. Vascular pathologies and cognition in a population-based cohort of elderly people. J Neurol Sci 2004;226:13-17.

30. Jellinger KA. Prevalence and impact of cerebrovascular lesions in Alzheimer and Lewy body diseases. Neurodegener Dis 2010;7:112-115.

31. Bendlin BB, Carlsson CM, Gleason CE, et al. Midlife predictors of Alzheimer's disease. Maturitas 2010;65:131-137.

\section{Disagree? Agree? Have a Question? Have an Answer?}

Respond to an article in Neurology ${ }^{\circledR}$ through our online Correspondence system:

- Visit www.neurology.org

- Access specific article on which you would like to comment

- Scroll to 'Responses' section in right-hand content box and click on "Submit a response"

- Enter contact information

- Upload your Correspondence

- Press "Send Response"

Correspondence will then be transmitted to the Neurology Editorial Office for review. Correspondence must be received within four weeks of the publication date of the article. Selected correspondence will subsequently appear in the print Journal. See our Information for Authors at www.neurology.org for format requirements. 


\section{Neurology}

\section{Nontraditional risk factors combine to predict Alzheimer disease and dementia Xiaowei Song, Arnold Mitnitski and Kenneth Rockwood}

Neurology 2011;77;227-234 Published Online before print July 13, 2011

DOI 10.1212/WNL.0b013e318225c6bc

This information is current as of July 13, 2011

\author{
Updated Information \& \\ Services
}

Supplementary Material

\section{References}

Citations

Subspecialty Collections

Permissions \& Licensing

Reprints including high resolution figures, can be found at: http://n.neurology.org/content/77/3/227.full

Supplementary material can be found at: http://n.neurology.org/content/suppl/2011/07/13/WNL.0b013e318225c 6bc.DC1

This article cites 29 articles, 9 of which you can access for free at: http://n.neurology.org/content/77/3/227.full\#ref-list-1

This article has been cited by 9 HighWire-hosted articles: http://n.neurology.org/content/77/3/227.full\#\#otherarticles

This article, along with others on similar topics, appears in the following collection(s):

\section{All Cognitive Disorders/Dementia}

http://n.neurology.org/cgi/collection/all_cognitive_disorders_dementia Alzheimer's disease

http://n.neurology.org/cgi/collection/alzheimers_disease

Cognitive aging

http://n.neurology.org/cgi/collection/cognitive_aging

Risk factors in epidemiology

http://n.neurology.org/cgi/collection/risk_factors_in_epidemiology

Information about reproducing this article in parts (figures,tables) or in its entirety can be found online at:

http://www.neurology.org/about/about_the_journal\#permissions

Information about ordering reprints can be found online:

http://n.neurology.org/subscribers/advertise

Neurology ${ }^{\circledR}$ is the official journal of the American Academy of Neurology. Published continuously since 1951, it is now a weekly with 48 issues per year. Copyright Copyright (? 2011 by AAN Enterprises, Inc.. All rights reserved. Print ISSN: 0028-3878. Online ISSN: 1526-632X.

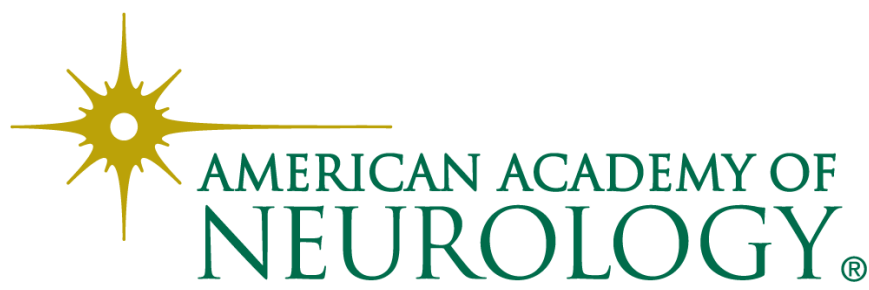

